\title{
Aa. Vv., Centuriae Latinae. II: Cent une figures humanistes de la Renaissances aux Lumières, à la mémoire de Marie-Madeleine de La Garanderie
}

\section{Michele Mastroianni}

\section{(2) OpenEdition \\ Journals}

\section{Edizione digitale}

URL: http://journals.openedition.org/studifrancesi/8853

DOI: $10.4000 /$ studifrancesi.8853

ISSN: 2421-5856

\section{Editore}

Rosenberg \& Sellier

\section{Edizione cartacea}

Data di pubblicazione: 1 octobre 2008

Paginazione: 438

ISSN: 0039-2944

\section{Notizia bibliografica digitale}

Michele Mastroianni, «Aa. VV., Centuriae Latinae. II: Cent une figures humanistes de la Renaissances aux Lumières, à la mémoire de Marie-Madeleine de La Garanderie», Studi Francesi [Online], 155 (LII | II) | 2008, online dal 30 novembre 2015, consultato il 13 janvier 2021. URL: http://journals.openedition.org/ studifrancesi/8853 ; DOI: https://doi.org/10.4000/studifrancesi.8853

Questo documento è stato generato automaticamente il 13 janvier 2021.

\section{cc) $($ ) $\ominus$}

Studi Francesi è distribuita con Licenza Creative Commons Attribuzione - Non commerciale - Non opere derivate 4.0 Internazionale. 


\section{Aa. Vv., Centuriae Latinae. II: Cent une figures humanistes de la Renaissances aux Lumières, à la mémoire de Marie- Madeleine de La Garanderie}

Michele Mastroianni 


\section{NOTIZIA}

Centuriae Latinae. II: Cent une figures humanistes de la Renaissances aux Lumières, à la mémoire de Marie-Madeleine de La Garanderie, réunies par Colette NATIVEL, Catherine MAGNIEN, Michel MAGNIEN, Pierre MARÉchauX et Isabelle PANTIN, Genève, Droz («Travaux d'Humanisme et Renaissance», n. CDXIV), 2006, pp. 863.

1 A quasi dieci anni dalla comparsa delle Centuriae Latinae. Cent une figures humanistes de la Renaissances aux Lumières offertes à Jacques Chomarat (Genève, Droz, 1997) esce il secondo volume dell'utilissimo repertorio di umanisti (questa volta in memoria di un'altra grande studiosa dell'Umanesimo) che, se si estende, è vero, fino alle soglie dell'Illuminismo (valga come esempio David van Hoogstraten, 1658-1724) e a volte risale al Quattrocento (per esempio, a Poggio Bracciolini) o addirittura al Medioevo (per esempio, a Giovanni di Salisbury), nella stragrande maggioranza offre schede concernenti autori cinquecenteschi, francesi ed europei. Grande è la bontà delle schede, veri articoli monografici, che offrono dati aggiornati alla più recente bibliografia. La scelta, pur ampia (basata anche sul criterio di tralasciare gli autori canonici di tutte le storie letterarie, quali Rabelais, Ronsard, Montaigne, ecc.), è in qualche misura arbitraria, in quanto testimonia gli interessi dei partecipanti (veramente numerosi) all'omaggio a M.-M de La Garanderie, ma ciò non sminuisce il pregio e l'utilità del repertorio, che unendo annotazioni su maiores e su minores permette una ricostruzione proficua dei milieux umanisti. 